\title{
PENGARUH RASIO STEP PADA SUDDEN ENLARGEMENT CHANNEL TERHADAP HEAT FLUX KONDENSASI DI POROUS MEDIA
}

\author{
Djoko Hari Praswanto1, Eko Siswanto², Nurkholis Hamidi² \\ 1, 2 Teknik Mesin Universitas Brawijaya Malang, MT Haryono 167, Malang 65145, Indonesia \\ Phone : +62-341-587710, Fax : +62-341-551430 \\ E-mail: djoko_harry@yahoo.de
}

\begin{abstract}
One of the most significant parameter in air conditioning problems is air humidity. A porous media can be used as a heat exchanger component in order to increase the heat transfer performance which is significantly depends on the heat flux values inside of them. To determine the heat flux value, a following test section was modeled in this research. A vapor passed through a channel whereas a particular porous media made of active carbon acted as its heat exchanger media. However, the sudden enlargement at the inlet of channel could affect the homogeneity of temperature distributions and also caused some several turbulencies. The research method is vapor flowed over the porous media for 60 minute with temperature of $300^{\circ} \mathrm{C}$. The vapor velocity is varied from $1 \mathrm{~m} / \mathrm{s}$ to $3 \mathrm{~m} / \mathrm{s}$ and the step ratio also varied between 0 until 1.66. From the experiment shows the bigger step ratio and vapor velocity results the bigger heat flux and air humidity after passed through the low porous media. Heat transfer was occured in porous media including convection heat transfer with the value of Gr/Re2 smaller than 1.
\end{abstract}

Keywords: air humidity, flow conditioner, heat flux, porous media, sudden enlargement.

PENDAHULUAN

Kelembapan udara merupakan jumlah uap air yang terkandung dalam udara. Pada umumnya kelembapan udara dipengaruhi oleh temperatur udara. Sehingga semakin rendah temperatur udara semakin banyak jumlah uap air yang terkandung dalam udara [1]. Apabila temperatur udara dibawah temperatur uap jenuh (vapor saturated) dengan tekanan 1 atmosfer (atm) maka akan terjadi perubahan fase, dari fase uap menjadi fase cair atau disebut dengan peristiwa kondensasi. Kondensasi pada awalnya terjadi berbentuk butiran-butiran yang menempel pada dinding permukaan (dropwise). Dari banyaknya butiran-butiran yang menempel pada dinding permukaan, nantinya akan saling berhubungan sehingga membentuk lapisan kondensasi pada dinding permukaan (filmwise) [2]. Kondensasi dapat dibedakan menjadi dua, yaitu kondensasi permukaan dan kondensasi kapiler. Kondensasi permukaan terjadi pada dinding permukaan, sedangkan kondensasi kapiler terjadi pada pori-pori permukaan. Kondensasi kapiler atau kondensasi mikro ini terjadi pada dinding permukaan yang berpori (porous media).
Untuk meminimalisir terjadinya kondensasi tergantung pada porous media yang digunakan. Semakin besar kemampuan media dalam menyerap air maka jumlah kondensat yang menempel pada dinding permukaan semakin sedikit. Mekanisme ini terjadi karena adanya gaya Van Der Walls yaitu gaya tarik-menarik antar molekul, atom atau ion [3]. Dalam penelitian kondensasi pada porous media ini yang dipakai adalah arang aktif. Pemakaian arang aktif didasarkan pada struktur dari arang aktif tersebut. Arang aktif mempunyai pori-pori yang lebih besar karena pada proses pengaktivasi secara kimia mengikat kotoran-kotaran yang menutupi poripori tersebut.

Tujuan dari kondensasi pada porous media ini dapat digunakan untuk mengontrol kelembapan. Selain memakai bahan yang mudah menyerap air pada dinding permukaan, dalam mengontrol kelembapan dapat juga dengan meningkatkan perpindahan panas. Hal ini disebabkan karena dengan meningkatkan perpindahan panas maka temperatur udara dapat meningkat sehingga jumlah uap air yang terkandung dalam udara sedikit. Pada umumnya, untuk meningkatkan perpindahan panas salah satunya dengan memperluas area 
permukaan perpindahan panas (extended surface). Dalam perkembangannya, untuk meningkatkan perpindahan panas dikembangkan model baru dengan fungsi yang sama yaitu porous media. Porous media mempunyai porositas yang dapat dilalui oleh aliran fluida. Dengan mempunyai porositas didalamnya sehingga luas permukaan perpindahan panas lebih besar dari pada benda padat (massive - solid) [4]. Pada porous media terdapat dua perpindahan panas yang terjadi yaitu konduksi dan konveksi. Konduksi terjadi ketika perpindahan panas tanpa diikuti berpindahnya massa zat. Sedangkan konveksi merupakan perpindahan panas yang terjadi dengan berpindahnya massa zat [5].

Pada penelitian oleh Katoh,Y. [6], perpindahan panas pada porous media dengan porositas acak di aliran laminar dengan metode Kinderman-Ramage didapatkan hasil bahwa pada porous media dengan porositas yang lebih besar dapat memberikan perpindahan panas yang lebih besar pula. Hal ini disebabkan dengan porositas yang lebih besar maka aliran dapat bergerak lebih bebas melalui rongga-rongga di dalam porous media [6]. Kemudian penelitian ini dikembangkan dengan porous media pada model aliran yang sama untuk mengetahui pengaruh perlakuan temperatur ambient terhadap aliran dinamik migrasi lateral kondensat dengan kelembapan yang berbeda. Tetapi untuk mendapatkan aliran laminer dalam eksperimen perpindahan panas pada porous media sulit didapatkan, karena pada desain porous media chamber di daerah inlet terdapat perbedaan diameter [7]. Karena terdapat pembesaran diameter secara tiba-tiba (sudden enlargement) sehingga aliran bergerak tidak beraturan.

Kecepatan udara masuk terhadap distribusi temperatur porous media sangat mempengaruhi. Dengan kecepatan udara masuk semakin besar maka distribusi temperatur porous media semakin tinggi. Dan laju perpindahan panas yang paling besar pada porous media didekat inlet [8]. Hal ini disebabkan karena pada porous media didaerah inlet terdapat sudden enlargement, maka terbentuk pancaran udara masuk sehingga pada daerah tersebut aliran fluida belum tersebar penuh ke porous media. Tetapi dengan memperbesar kecepatan udara masuk dapat mengakibatkan vortex pada porous media, sehingga semakin kecil massa dari porous media, vortex yang terjadi semakin besar pula. Untuk menjaga agar distribusi temperatur udara masuk dapat tersebar lebih merata dan menghindari vortex maka perlu ditambahkan flow conditioner pada inlet chamber porous media. Selain itu dengan menambahkan flow conditioner lebih mudah mendapatkan bentuk aliran laminer udara masuk setelah melewati sudden enlargement [9].

Mengacu pada penelitian yang dilakukan oleh Zenitha, Ika R. Et. Al. [9], maka pada penelitian ini dilakukan penambahan step pada daerah inlet. Penambahan step berfungsi sebagai flow conditioner agar distribusi temperatur udara masuk dapat tersebar secara merata, mengurangi vortex pada porous media serta untuk mendapatkan aliran laminer didalam chamber porous media. Dengan adanya sudden enlargement pada inlet chamber porous media sehingga aliran udara setelah melewati sudden enlargement akan membentuk pancaran yang memanjang. Panjang dari pancaran tersebut dipengaruhi dari kecepatan aliran udara masuk. Semakin tinggi kecepatan aliran udara masuk maka semakin panjang pancaran aliran udara tersebut sehingga mempengaruhi distribusi temperatur pada porous media [10]. Dengan penambahan step ini diharapkan dapat mengkondisikan aliran udara masuk setelah melewati sudden enlargement agar dapat meminimalisir pancaran aliran yang berkontak langsung dengan porous media sehingga distribusi temperatur pada porous media dapat tersebar secara merata dan menghindari vortex pada porous media.

Atas dasar ini maka perlu dilakukannya penelitian untuk mengkaji dan mengamati pengaruh rasio step terhadap heat flux kondensasi pada porous media guna mendapatkan aliran yang steady setelah melewati sudden enlargement pada inlet chamber porous media. 
Dalam perhitungan heat flux digunakan Pers. 1 sebagai berikut

$$
\frac{q^{\prime \prime}}{A}=k \cdot \frac{T_{1}-T_{2}}{Z}
$$

Dimana :

$q^{\prime \prime}=$ Heat flux $\left(\mathrm{W} / \mathrm{mm}^{2}\right)$

$A=$ Luas porous media $\left(\mathrm{mm}^{2}\right)$

$k=$ Konduktivitas termal $\left(\mathrm{W} / \mathrm{m} .{ }^{\circ} \mathrm{C}\right)$

$T_{1}=$ Tempeatur awal $\left({ }^{\circ} \mathrm{C}\right)$

$T_{2}=$ Temperatur Akhir $\left({ }^{\circ} \mathrm{C}\right)$

$Z=$ Ketebalan kondensat

Karena pada penelitian ini terdapat 2 konduktivitas termal yang berbeda yaitu konduktivitas termal porous media terisi air dan konduktivitas termal terisi udara maka konduktivitas termal yang digunakan dalam Pers. 1 diatas menggunakan konduktivitas termal efektif.

Dari Gambar 1 diatas sehingga didapatkan Pers. 2 seperti dibawah ini.

$$
K_{e f f}=\frac{k^{\prime} \cdot k^{\prime \prime} \cdot Z}{\left[k^{\prime \prime} \cdot \delta+(1-\delta)\right]}
$$

Dimana:

$K_{\text {eff }}=$ kKonduktivitas termal efektif keseluruhan pada lapisan porous media

$k^{\prime}=$ konduktifitas termal porous media dengan kondensat

$k^{\prime \prime}=$ konduktifitas termal porous media

$Z \quad=$ tebal porous media

$\delta \quad=$ tebal kondensat

$\varepsilon \quad=$ porositas

$k p=$ konduktifitas termal partikel

$k L=$ konduktifitas termal kondensat

$k a=$ konduktifitas termal udara

$L \quad=$ luas permukaan media

\section{METODOLOGI PENELITIAN}

Metode yang digunakan pada penelitian ini menggunakan metode eksperimental yaitu dengan pengamatan langsung untuk mencari sebab akibat dari fenomena yang terjadi. Pada penelitian ini porous media yang digunakan adalah arang aktif. Arang aktif ini dimasukkan kedalam test section), kemudian di atas porous media dialiri uap dengan temperatur 30 ${ }^{\circ} \mathrm{C}$ selama 60 menit. Kecepatan uap masuk divariasikan, yaitu $1 \mathrm{~m} / \mathrm{s}, 2 \mathrm{~m} / \mathrm{s}$ dan $3 \mathrm{~m} / \mathrm{s}$. Langkah ini dilakukan berulang-ulang dengan rasio step divariasikan, yaitu tanpa step, 0,33 , $0,66,1,1,33$ dan 1,66 .

Alat penelitian yang digunakan pada penelitian ini yaitu kompresor, pemanas, tangki humidifier, mesin pendingin dan data logger yang dirangkai seperti pada Gambar 1.

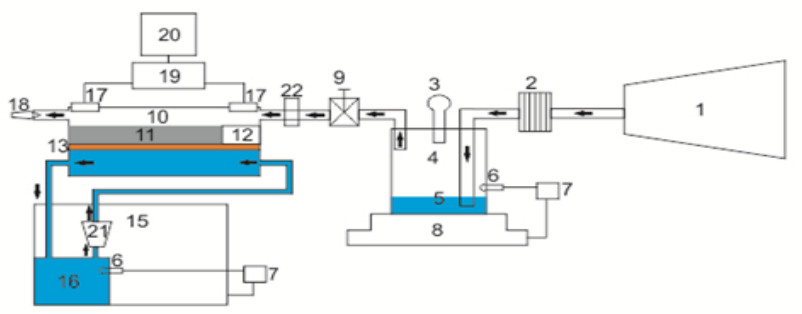

Keterangan :

1. Kompresor

2. Filter udara

3. Pressure gauge

4. Tangki humidifier

5. Air

6. Termokopel

7. Termokontrol

8. Pemanas

9. Regulator

10. Ruang kondensas

11. Arang aktif
12. Step (flow conditioner)
13. Plat tembaga
14. Ruang air dingin
15. Mesin pendingin
16. Air dingin
17. Sensor humidity
18. Pitot tube
19. Data logger
20. Monitor
21. Pompa air dingin
22. Flow meter

Gambar 1 Desain alat penelitian

Pada gambar 1 diatas, dimulai dari pengisian air kedalam tangki humidifier, kemudian kompresor dihidupkan untuk memberikan tekanan pada tangki humidifier. Udara dari kompresor mengalir ke tangki humidifier melewati filter udara agar air yang terkandung pada udara dari kompresor tersaring. Bersamaan dengan kompresor, pemanas dihidupkan sampai temperatur 30 ${ }^{\circ} \mathrm{C}$. Untuk menjaga temperatur tetap konstan pemanas dilengkapi dengan termokontrol yang berfungsi mematikan pemanas secara otomatis sesuai set up temperatur. Selain itu, mesin pendingin yang sudah terisi air dihidupkan sampai temperatur $10{ }^{\circ} \mathrm{C}$. Untuk mendapatkan temperatur tersebut terjaga konstan mesin pendingin dilengkapi dengan termokontrol. Kemudian test section dipersiapkan dengan mengisi porous media arang aktif didalam test section dan memasang termokopel untuk melihat 
temperatur pada porous media. Setelah itu termal efektif dipengaruhi oleh ketebalan data logger dihidupkan dan dihubungkan ke kondensat yang terserap oleh porous media monitor. Apabila temperatur uap sudah sehingga semakin lama waktu yang digunakan mencapai $30{ }^{\circ} \mathrm{C}$ dan temperatur air dingin maka uap air yang terkandung didalam aliran sebesar $10{ }^{\circ} \mathrm{C}$, maka pompa air dingin masuk test section semakin banyak diserap dihidupkan untuk mengalirkan air dingin dan oleh porous media.

regulator dibuka serta mengatur kecepatan sesuai variasi dengan flowmeter. Arah aliran uap dan air dingin sesuai dengan arah panah pada gambar 4.8. Setelah itu dilakukan pengamatan fenomena penyerapan kondensat oleh porous media di test section dan monitor yang terhubung dengan data logger untuk melihat perubahan temperatur dan kelembapan. Setelah didapatkan data pengujian, maka dihitung konduktivitas termal efektif, heat flux, Reynold Number, Grashof number dan kelembapan.

\section{HASIL DAN PEMBAHASAN}

\section{Pengaruh waktu terhadap konduktivitas termal efektif}

Dari hasil penelitian, dilakukan pehitungan konduktivitas termal efektif sehingga didapatkan grafik pengaruh waktu terhadap konduktivitas termal efektif sebagai berikut.

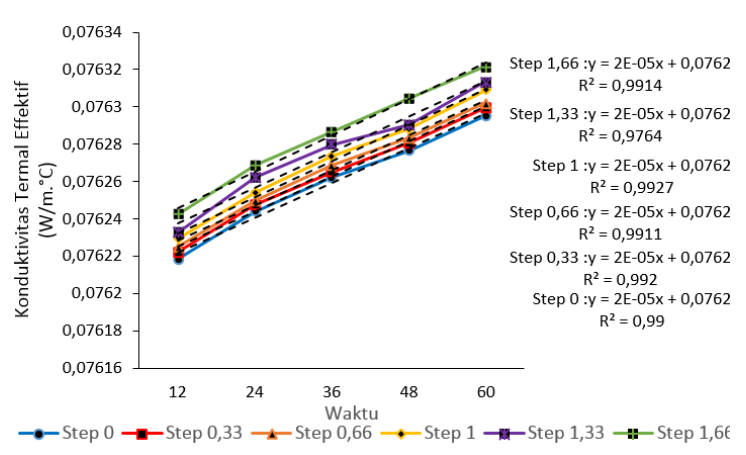

Gambar 2 Grafik pengaruh waktu terhadap konduktivitas temal efektif

Berdasarkan Gambar 2 diatas, secara umum konduktivitas termal efektif (Keff) terhadap waktu (t), menunjukkan peningkatan Keff seiring pertambahan waktu. Ditinjau dari nilai korelasi pada gambar diatas, rata-rata memiliki nilai diatas 0,95 , sehingga hubungan antara konduktivitas termal efektif dengan waktu sangat berpengaruh, artinya besarnya konduktivitas termal efektif dipengaruhi oleh waktu. Hal ini disebabkan karena konduktivitas

\section{Pengaruh perubahan rasio step \\ a. Konduktivitas termal efektif}

Dari data pengujian yang diperoleh, dilakukan perhitungan konduktivitas termal efektif untuk tiap rasio step menggunakan Pers. 1 sehingga diperoleh hubungan seperti ditampilkan pada Gambar 3.

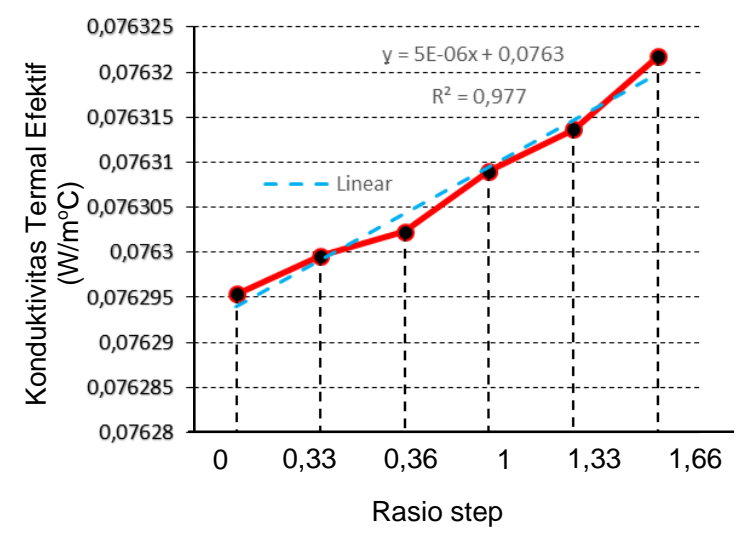

Gambar 3 Grafik konduktivitas termal efektif

Berdasarkan Gambar 3, pengaruh rasio step terhadap konduktivitas termal efektif dengan kecepatan uap masuk $1 \mathrm{~m} / \mathrm{s}$ mengalami peningkatan. Puncak tertinggi pada grafik tersebut ditunjukkan pada step 1,66 dengan nilai konduktivitas termal efektif $0,0763217 \mathrm{~W} / \mathrm{m}^{\circ} \mathrm{C}$. Secara umum, setiap perubahan rasio step menyebabkan perubahan nilai konduktivitas termal efektif. Semakin besar rasio step maka aliran yang terjadi didalam test section mendekati aliran laminer. Dengan aliran uap yang laminer distribusi temperatur yang diberikan dapat tersebar lebih merata, karena dalam test section di daerah inlet terjadi pembesaran diameter secara tiba-tiba (sudden enlargement) yang dapat mengakibatkan turbulensi dan pancaran aliran sehingga dengan terjadinya fenomena ini dapat mengakibatkan distribusi temperatur tidak bisa tersebar secara merata. Dengan adanya step, maka dapat mengkondisikan aliran uap 
sehingga distribusi temperatur bisa tersebar lebih merata. Oleh karena itu dengan semakin meratanya temperatur uap yang diberikan maka kondensat yang terserap semakin banyak. Tidak meratanya distribusi temperatur uap yang diberikan dapat dilihat dari gambar penyerapan kondensat oleh porous media.

\section{b. Heat flux pada porous media}

Dari hasil data perhitungan konduktivitas termal efektif, kemudian melakukan perhitungan heat flux dengan menggunakan persamaan 1 , sehingga didapatkan grafik seperti dibawah.

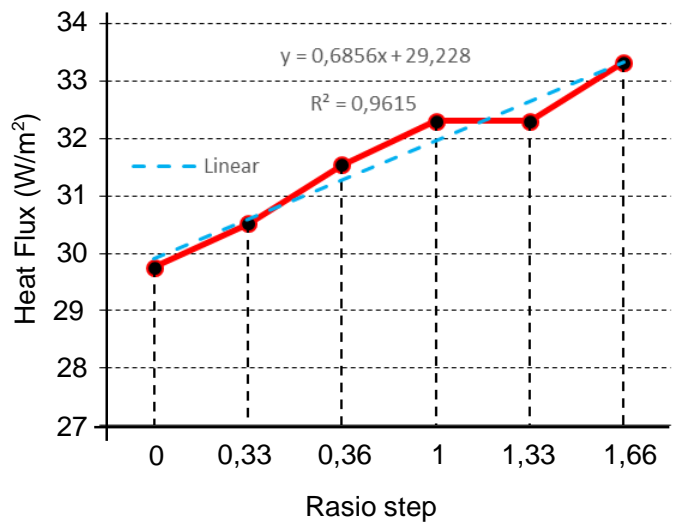

Gambar 4 Grafik rasio step terhadap heat flux

Hubungan antara step rasio dengan heat flux ditampilkan pada Gambar 4 di atas. Tampak adanya peningkatan nilai heat flux setiap perubahan rasio step. Dikarenakan semakin besar rasio step maka konduktivitas termal efektif semakin tinggi sehingga nilai heat flux pada porous media semakin besar. Pada persamaan 1 bahwa dalam perhitungan heat flux dipengaruhi oleh konduktivitas termal efektif dan selisih temperatur. Sehingga dengan tingginya nilai konduktivitas termal efektif maka nilai heat flux juga semakin tinggi.

\section{c. Reynold Number}

Dari Gambar 5 grafik pengaruh rasio step terhadap Reynold Number menunjukkan bahwa dengan bertambah besar rasio step maka Reynold Number semakin kecil. Aliran yang mempunyai Reynold Number $<2300$ merupakan aliran laminer, 2300-4000 aliran transisi dan $>4000$ aliran turbulen [10].

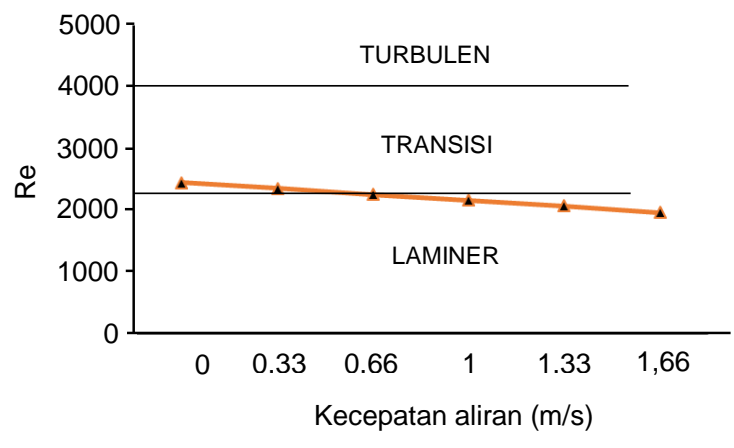

Gambar 5 Grafik rasio step terhadap Reynold Number

Pada Gambar 5 ditunjukkan kondisi tanpa menggunakan step mempunyai Reynold Number sebesar 2429,66 sehingga termasuk dalam jenis aliran transisi. Sedangkan pada step 0,66 mempunyai Reynold Number 2242,92 termasuk dalam jenis aliran laminer. Hal ini dikarenakan dengan adanya step pada sudden enlargement channel dapat mengkondisikan aliran uap masuk karena dengan adanya step perubahan diameter pipa tidak berubah secara drastis sehingga aliran masuk dapat terkondisikan menjadi aliran laminer.

\section{d. Regime Konvektiv}

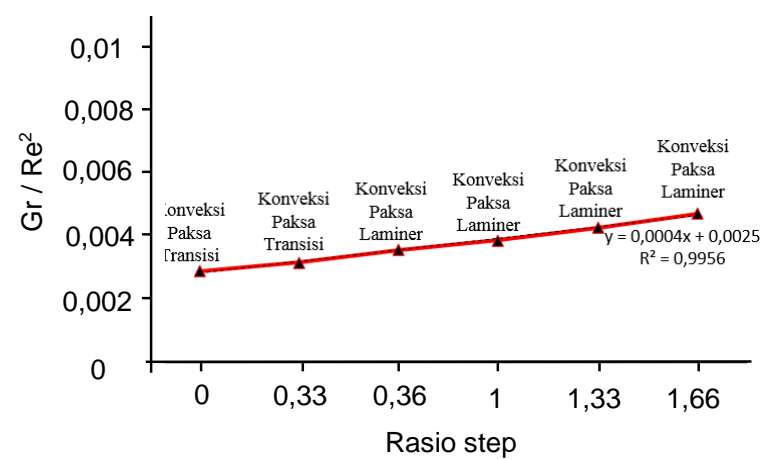

Gambar 6 Grafik $\mathrm{Gr} / \mathrm{Re}^{2}$

Konveksi paksa mempunyai nilai $\mathrm{Gr} / \mathrm{Re}^{2}$ $<0,1$, konveksi campuran $0,1 \leq \mathrm{Gr} / \mathrm{Re}^{2} \leq 10$, konveksi natural $\mathrm{Gr} / \mathrm{Re}^{2}>10$ [11]. Dari gambar98 diatas secara umum kondensasi pada porous media dalam ruang lingkup konveksi paksa. Hal ini dikarenakan pada penelitian ini dengan perubahan rasio step pada kecepatan uap masuk $1 \mathrm{~m} / \mathrm{s}$ mempunyai nilai $\mathrm{Gr} / \mathrm{Re}^{2}<0,1$. 
Hubungan antara $\mathrm{Gr} / \mathrm{Re}^{2}$ dengan rasio step berbanding lurus seperti ditunjukkan pada Gambar 6 dimana peningkatan nilai rasio step akan dihasilkan nilai $\mathrm{Gr} / \mathrm{Re}^{2}$ yang semakin besar. Hal ini dikarenakan nilai $\mathrm{Gr} / \mathrm{Re}^{2}$ dipengaruhi dari Reynold Number, semakin kecil Reynold Number maka semakin besar nilai $\mathrm{Gr} / \mathrm{Re}^{2}$. Sehingga dengan semakin besar rasio diperoleh nilai $\mathrm{Gr} / \mathrm{Re}^{2}$ yang besar karena rasio step semakin besar mempunyai Reynold Number yang kecil.

\section{Pengaruh kecepatan uap masuk}

\section{a. Konduktivitas termal efektif}

Besarnya kecepatan uap yang masuk akan mempengaruhi nilai dari konduktivitas termal yang diperoleh menggunakan Pers. 2 seperti ditunjukkan pada Gambar 7 berikut.

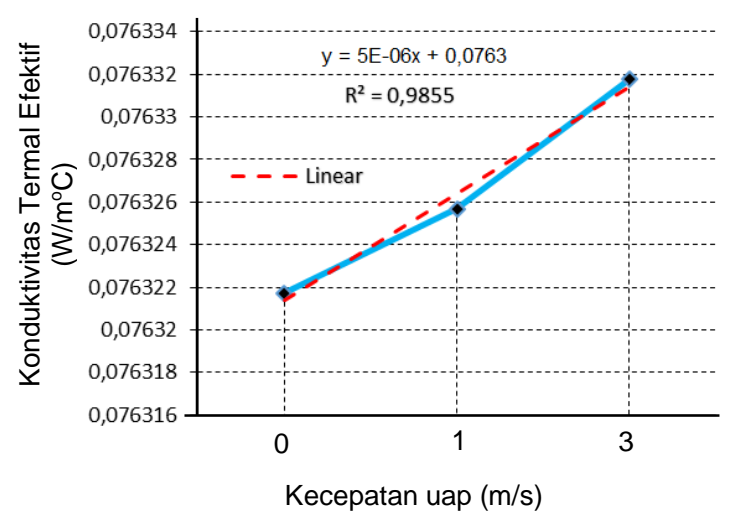

Gambar 7 Grafik kecepatan uap masuk terhadap konduktivitas termal efektif

Dari Gambar 7 terlihat bahwa semakin tinggi kecepatan uap maka nilai konduktivitas termal efektif semakin besar. Semakin tinggi kecepatan uap menyebabkan tertahannya uap didalam test section karena pada outlet test section terdapat sudden contraction sehingga aliran uap yang keluar lebih sedikit dibandingkan aliran uap yang masuk. Oleh karena itu dengan tertahannya uap didalam test section memberi kesempatan porous media untuk menyerap air yang terkandung didalam uap. Dengan banyaknya uap yang tertahan didalam test section maka kondensat yang terserap oleh porous media akan lebih banyak.
Dengan perbedaan ketebalan kondensat yang terserap oleh porous media pada setiap perubahan step, maka diperoleh nilai heat flux yang berbeda. Semakin tebal kondensat yang terserap maka nilai heat flux akan semakin tinggi. Hal ini disebabkan karena heat flux dipengaruhi nilai konduktivitas termal efektif yang cenderung meningkat.

\section{b. Heat flux pada porous media}

Hubungan antara kecepatan uap dengan heat flux ditunjukkan pada Gambar 8. Ditinjau dari perubahan kecepatan aliran uap masuk, nilai heat flux pada porous media semakin tinggi. Pada pembahasan sebelumnya, dengan semakin tinggi kecepatan uap mempunyai nilai konduktivitas termal efektif yang tinggi sehingga nilai heat flux akan meningkat karena nilai heat flux dipengaruhi oleh besarnya konduktivitas termal efektif. Hal ini dapat dibuktikan bahwa pada Gambar 8 diatas mempunyai nilai korelasi 0,987 sehingga dapat disimpulkan bahwa dengan nilai korelasi seperti itu kecepatan uap mempengaruhi nilai heat flux. Hal ini dikarenakan pada statistik perhitungan korelasi, apabila nilai korelasi sama dengan nol maka tidak berpengaruh, nilai korelasi antara 0,1 sampai dengan 0,3 kurang berpengaruh, 0,4 sampai dengan 1 sangat berpengaruh.

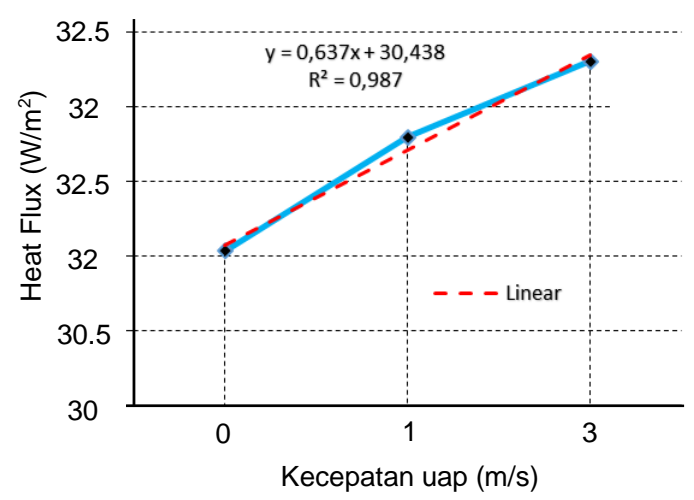

Gambar 8 Grafik heat flux

Pada Gambar 8 diatas, menunjukkan nilai heat flux pada kecepatan $3 \mathrm{~m} / \mathrm{s}$ merupakan nilai heat flux tertinggi. Pada gambar tersebut membuktikan dengan bertambahnya kecepatan uap maka nilai heat flux juga meningkat. 


\section{c. Reynold Number}

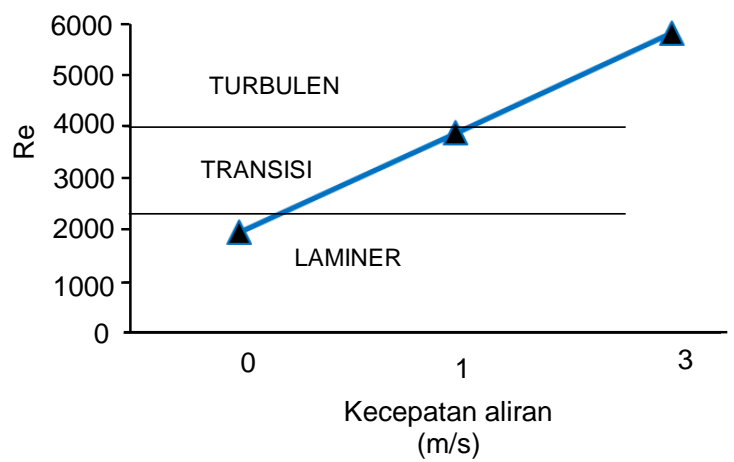

Gambar 9 Grafik kecepatan uap terhadap Reynold Number

Pada Gambar 9, terjadi peningkatan trend, semakin tinggi kecepatan semakin besar Reynold Number. Hal ini dikarenakan, Reynold Number berbanding lurus dengan kecepatan aliran sehingga dengan semakin besar Reynold Number bentuk aliran yang terjadi aliran turbulen. Pada penelitian ini dengan kecepatan $3 \mathrm{~m} / \mathrm{s}$ terjadi sedikit vortex pada porous media karena pada kecepatan ini aliran uap yang masuk pada test section merupakan aliran turbulen. Tetapi dengan semakin tinggi kecepatan masuk uap dapat meningkatkan nilai heat flux karena semakin tinggi kecepatan masuk maka uap yang terdapat didalam test section semakin banyak dikarenakan pada outlet test section terjadi sudden contraction sehingga uap yang keluar dari test section sedikit, oleh karena itu kondensat yang terserap semakin banyak dan nilai heat flux semakin tinggi.

\section{d. Regime Konvektiv}

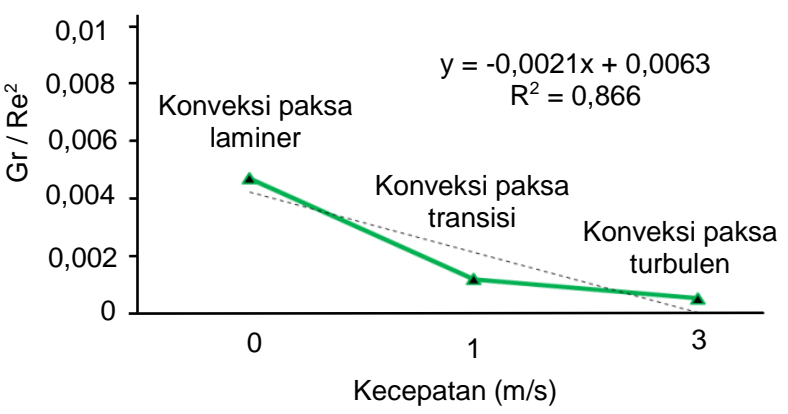

\section{Gambar 10 Grafik pengaruh kecepatan terhadap $\mathrm{Gr} / \mathrm{Re} 2$}

Pada Gambar 10 terjadi penurunan tren, hal ini dikarenakan dengan kecepatan semakin tinggi mempunyai Reynold Number yang besar sehingga nilai $\mathrm{Gr} / \mathrm{Re}^{2}$ kecil karena nilai $\mathrm{Gr} / \mathrm{Re}^{2}$ berbanding terbalik dengan Reynold Number. Pada grafik diatas, secara umum, rezim konvektiv termasuk konveksi paksa. Tetapi mempunyai konveksi paksa yang berbeda yaitu, pada kecepatan $1 \mathrm{~m} / \mathrm{s}$ konveksi paksa laminer, kecepatan $2 \mathrm{~m} / \mathrm{s}$ konveksi paksa transisi dan kecepatan $3 \mathrm{~m} / \mathrm{s}$ konveksi paksa turbulen.

\section{e. Kelembapan setelah melewati porous media}

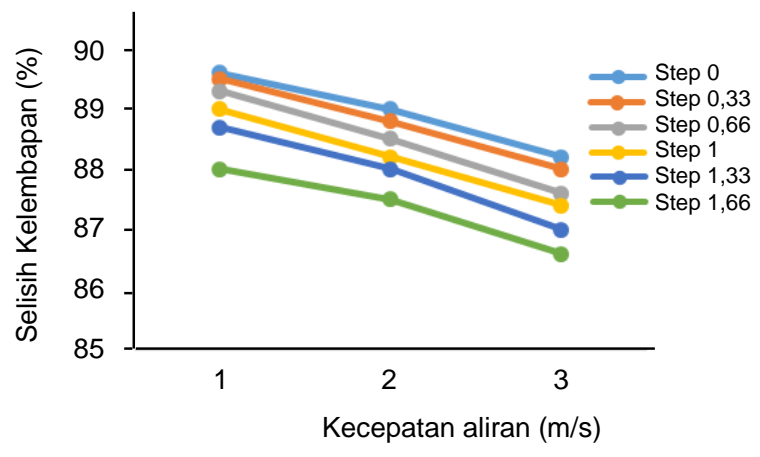

Gambar 11 Grafik kelembapan setelah
melewati porous media

Pada Gambar 11 menjelaskan tren penurunan kelembapan akibat dari perbedaan kecepatan uap masuk. Puncak terendah nilai kelembapan pada step 1,66 dengan kecepatan $3 \mathrm{~m} / \mathrm{s}$. Kelembapan dipengaruhi kecepatan pergerakan angina (uap) [12]. Sehingga semakin tinggi kecepatan uap masuk maka kelembapan semakin kecil.

Ditinjau dari ketebalan kondensat, pada step 1,66 kondensat yang terserap oleh porous media banyak sehingga uap setelah melewati porous media mempunyai nilai kelembapan yang rendah. Hal ini dikarenakan uap pada saat didalam test section pada step 1,66 dan kecepatan $3 \mathrm{~m} / \mathrm{s}$ tertahan lama didalam test section sehingga porous media dalam menyerap air yang terkandung dalam uap semakin lama, oleh karena itu kondensat pada step 1,66 dengan kecepatan $3 \mathrm{~m} / \mathrm{s}$ 
banyak terserap dan uap yang keluar dari test section mempunyai kadar air yang kecil.

\section{KESIMPULAN}

Dari studi eksperimental ini, pengaruh rasio step pada sudden enlargement channel pada kondensasi di porous media dapat disimpulkan fenomena heat flux dan kelembapan pada test section sebagai berikut:

1. Dengan bertambahnya waktu tebal kondensat semakin besar sehingga nilai konduktivitas termal efektif semakin tinggi.

2. Dengan semakin besar rasio step dapat meningkatkan konduktivitas termal efektif dengan fenomena ketebalan kondensat yang bertambah.

3. Ketebalan kondensat yang bertambah tebal maka nilai heat flux pada porous media semakin tinggi. Sehingga semakin besar rasio step maka laju perpindahan panas pada porous media semakin tinggi.

4. Rezim konvektif yang terjadi pada heat flux kondensasi porous media ini merupakan perpindahan panas konveksi secara paksa.

5. Semakin tinggi kecepatan aliran uap masuk maka uap didalam test section semakin banyak dikarenakan pada outlet test section terjadi sudden contraction sehingga kondensat yang terserap semakin banyak, oleh karena itu heat flux pada porous media semakin meningkat.

6. Semakin besar rasio step maka kelembapan setelah melewati porous media semakin rendah, hal ini dikarenakan uap air yang terkandung dalam aliran terserap lebih banyak, hal ini dibuktikan dengan semakin besar rasio step kondensat yang terserap semakin banyak sehingga aliran udara setelah melewati porous media mempunyai kadar air yang kecil.

\section{DAFTAR PUSTAKA}

[1] Sura, Sunarto. A, 2013, Kelembapan Relatif Udara Pada Tempat, Universitas Hasanudin, Makasar.

[2] Hermana Joni dan boedisantoso rachman, 2010. Kondensasi, power point buku ajar, Surabaya.

[3] Setyawan, Eko Y. Et. Al.2014, Heat flux Kondensasi Pada Porous media Arang Tempurung Kelapa, Jurnal Rekayasa
Teknik Mesin Universitas Brawijaya, Malang.

[4] Siswanto, Eko, 2012, Study on Heat Transfer Phenomenon and Condensate Flow Dynamics during Condensation in Porous Media, Yamaguchi University., Japan.

[5] Holman, J.P., 1993, Perpindahan Kalor, Edisi 6, terjemah Ir. E. Jafisi, Msc. NewYork : Mc. Graw Hill, Ltd.

[6] Katoh,Y., Katsurayama, H., Nagata, R., and Siswanto, E, 2011, Influence of surface filmed particle of packed bed on wettability, proc. of annual meeting on Japanese Society on Multiphase Flow, in Japanese, 292-293

[7] Siswanto, Eko, Yasuo. Katoh. and Hiroshi Katsurayama, 2010, Forced laminar convective condensation in porous media, Proc. 47th National Heat Transfer Symp., Japan, pp. 135-136.

[8] Rahana, Angga V. Et. Al., 2013, Analisa Pengaruh Kecepatan Udara Masuk Terhadap Distribusi Temperatur Pada Porous Media, Jurnal Rekayasa Teknik Mesin Universitas Brawijaya, Malang.

[9] Zenitha, Ika R. Et. Al., 2013, Analisa Pengaruh Udara Masuk Terhadap Distribusi Temperatur Pada Porous Media, Jurnal Rekayasa Teknik Mesin Universitas Brawijaya.

[10] McDonough, J. M., 2009, Lectures in Elementary Fluid Dynamics: Physics, Mathematics and Application, Lecture Notes, Lexington: Departments of Mechanical Engineering and Mathematics, University of Kentucky.

[11] Jodat. A and Moghiman. M, 2012, An experimental assessment of the euapation correlations for natural, forced and combined convection regimes, Journal of Mechanical Engineering Science, 226: 145 originally published online 14 September 2011.

[12] Umar,M.R., 2013, Penuntun Ekologi Umum,Universitas Hasanuddin,Makassar. 